\title{
ПРОДУКТИВНОСТЬ И АДАПТИВНОСТЬ СОРТООБРАЗЦОВ ЛЮЦЕРНЫ В УСЛОВИЯХ ЛЕСОСТЕПИ СРЕДНЕГО ПОВОЛЖЬЯ
}

\section{И. В. Епифанова, канд. с.-х. наук; О. А. Тимошкин, доктор с.-х. наук}

Федеральное государственное бюджетное научное учреждение «Федеральный научный центр лубяных культур», Россия, Пензенская обл., р. п. Лунино, e-mail: oatimoshkin@mail.ru

Исследования проводили на опытном поле Пензенского ИСХ - филиала ФГБНУ ФНЦ ЛК в 2013-2016 годах. Цель исследований - оценить продуктивность новых сортообразцов люцерны и параметры их адаптивности к лимитирующим фракторам среды при возделывании в одновидовом посеве. В среднем за годы исследований продуктивность сухого вещества сортообразцов люцерны колебалась от 6,72 до 12,21 т/га в зависимости от индекса условий среды $\left(I_{i}-3,55-1,85\right)$. Лучшим по продуктивности является сортообразец Популяция 11/15 с урожайностью 11,42 т/га (+ 7,6 \% к st.). Изменчивость продуктивности сухого вещества варьирует от 23,0 до $27,2 \%$, что характеризует среднюю стабильность признака. Изучаемые образцы люцерны показали высокую экологическую адаптивность и пластичность, значения bi варьировали в пределах 0,86-1,26. Наиболее стабильными и пластичными по продуктивности сухого вещества являются сортообразцы: Стабильная $-\mathrm{bi}=0,90 ; \sigma^{2}{ }^{2}=$ 1,11 ; Популяция $10 / 14-b i=0,98 ; \sigma d^{2}=0,68$. Семенная продуктивность образцов люцерны в среднем за годы исследований колебалась от 0,36 до 0,67 т/га в зависимости от индекса условий среды $\left(\mathrm{I}_{\mathrm{i}}=-0,15 \ldots 0,15\right)$. Лучшим по урожайности семян является сортообразец Мечта + Биотип $4-0,67$ т/га (+ 21,8\% к st.). Изменчивость урожайности семян у стандарта Камелия была слабой - 9,4 \%; средняя изменчивость урожайности $(24,1-27,4$ \%) была у образцов Популяция 8, Корнеотпрысковая 1 и Корнеотпрысковая 2. Более высоким показателем уровня стабильности сорта характеризовались стандарт Камелия и Мечта + Биотип 4, индекс стабильности (ИС) которых составил 0,18 и 0,32, соответственно. Наиболее стабильными и пластичными сортами по урожайности семян являются сортообразцы: Популяция $11 / 15-b i=-1,05 ; \sigma d r^{2}=0,16 ;$ Стабильная $-b i=-0,90 ; \sigma d r^{2}=0,16 ;$ ПП урожай $07-b i=-$ 1,$04 ; \sigma d r^{2}=0,08$.

Ключевые слова: люцерна, сортообразец, конкурсное сортоиспытание, сбор сухого вещества, урожайность семян, адаптивность.

\section{Введение}

С целью снижения значительных потерь в растениеводческой продукции и ущерба в экономике сельского хозяйства крайне необходима разработка эффективных приёмов и методов селекции для создания адаптивных, пластичных, высокопродуктивных сортов, устойчивых к экстремальным условиям среды [3, 4, 7, 15].

В повышении урожайности той или иной культуры ведущая роль принадлежит сорту. Поэтому следует развивать концепцию внедрения таких сортов, которые способны эффективно использовать местные условия роста и развития (тепло, влагу, питательные вещества, и др.), обладать широкой адаптивной способностью и обеспечивать стабильную урожайность. При этом необходим агрономический баланс между продуктивностью и стабильностью сорта $[2,6,9,14,17]$.

Люцерна - одна из лучших бобовых трав для приготовления высокобелковых кормов (зеленой массы, сена, сенажа, силоса и др.). Она является хорошим предшественником для многих сельскохозяйственных культур после двух, трех летнего возделывания накапливает в почве около 10-12 т/га корней и пожнивных остатков, которые по содержанию макроэлементов равноценны внесению 4-7 т/га навоза. Поэтому, как наиболее урожайная в Средневолжском регионе кормовая культура, люцерна получила наибольшее распространение [1, 13].

В Пензенском ИСХ ведётся работа по созданию высокопродуктивных, экологически устойчивых сортов люцерны разного типа использования [5]. В качестве исходного материала используются образцы различного эколого-географрического происхождения (ФИЦ ГНЦ ВИГРР им. Н. И. Вавилова, ФНЦ ВИК им. В. Р. Вильямса, ТатНИИСХ, собственный селекционный материал).

Цель исследований - оценка продуктивности и основных параметров адаптив- 
ности к лимитирующим факторам среды новых сортообразцов люцерны при возделывании в одновидовом посеве.

Методы и материалы

Исследования проводили на опытном поле Пензенского ИСХ. Почва - чернозём выщелоченный среднемощный тяжелосуглинистый с содержанием в пахотном горизонте гумуса (по Тюрину) 6,4-6,5 \%; $\mathrm{pH}_{\text {сол }}$ 5,4-5,6, подвижного фросфора (по Чирикову) - 145-146 и обменного калия (по Чирикову) - 140-155 мг на кг почвы.

Посев в питомниках конкурсного сортоиспытания (КСИ) - летний, беспокровный. Норма высева - 6 млн./га. Площадь делянки - $10 \mathrm{~m}^{2}$, повторность - четырехкратная. Стандарт - сорт Камелия. Уборку зелёной массы проводили в фразе бутонизации начала цветения люцерны.

Закладку полевых питомников, наблюдения, оценки, учеты проводили в соответствии с Методическими указаниями по селекции многолетних трав (1985), Методическими указаниями по селекции и первичному семеноводству многолетних трав (1993) [10, 11]. Экологическую устойчивость сортов определяли по методике A. A. Rossielle и J. Hamblin (по уравнению $Y_{\max }-Y_{\min }$ ) [18]. Параметры общей адаптивной способности (bi) и стабильности $\left(\mathrm{S}^{2} \mathrm{~d}_{1}\right)$ - по методике А. В. Кильчевского и Л. В. Хотылевой с помощью дисперсионного и регрессионного анализов [8]. Индекс условий среды - по методике S. A. Eberhart и W. A. Russel [16]. Индекс стабильности (ИС) и показатель уровня стабильности сорта (ПУСС) определяли по методике, описанной Э. Д. Неттевичем [12].

Климат зоны проведения исследований характеризуется достаточным и частично умеренным увлажнением. Гидротермический коэфффициент (ГТК) 1,1-0,9 ед. За год выпадает 450-500 мм осадков, из них за период вегетации (май-сентябрь) - 250-280 мм.
По теплообеспеченности зона прохладная и умеренно тёплая. Сумма положительных температур выше $+10{ }^{\circ} \mathrm{C}$ составляет 2200-2400 ${ }^{\circ} \mathrm{C}$. Период активной вегетации растений 136-142 дня. Безморозный период - 125-138 дней.

В условиях 2013 года с апреля по октябрь выпало 348 мм осадков и ГТК составил 1,3 ед. Условия вегетации 2014 года были благоприятными для семенной и кормовой продуктивности. С апреля по октябрь выпало 176 мм осадков, ГТК составил 0,7 ед., что характеризует период недостаточного увлажнения. В 2015 году количество осадков в период вегетации составило 236 мм, характер их выпадения был крайне неравномерен. С апреля по октябрь ГТК составил 0,81 ед. С апреля по октябрь 2016 года выпало 311 мм осадков (норма 233 мм), ГТК = 1,32 ед.

Результаты

При возделывании на корм индекс условий среды варьировал в довольно широких пределах от -3,55 до 1,85 единиц. Наиболее стрессовые условия для развития вегетативной массы люцерны сложились в 2015 году, величина индекса условий среды составила 3,55. Наиболее оптимальными условиями для развития люцерны был 2013 год с показателем индекса условий соответственно - 1,85.

В соответствии с условиями среды варьировала и урожайность сухого вещества у сортообразцов люцерны. В среднем за 2013-2016 годы продуктивность сортообразцов люцерны колебалась от 9,38 до 11,42 т/га (табл. 1).

Лучший по урожайности сухого вещества образец Популяция 11/15 с продуктивностью 11,42 т/га (+ 7,6 \% к st). Изменчивость продуктивности сухого вещества у сортообразцов люцерны варьирует от 23,0 до $27,2 \%$, что характеризует среднюю стабильность сортов. По показателю уровня

Таблица 1

Показатели варьирования сбора сухого вещества сортообразцов люцерны в питомнике КСИ (в среднем за 2013-2016 га.)

\begin{tabular}{|c|l|c|c|c|c|}
\hline №/Д & Сортообразец & $\begin{array}{c}\text { Средняя } \\
\text { урожайность, } \\
\text { т/га }\end{array}$ & $\begin{array}{c}\text { Изменчивость } \\
\text { урожайности } \\
\text { Сv, \% }\end{array}$ & $\begin{array}{c}\text { Индекс } \\
\text { стабильности } \\
\text { (ИС) }\end{array}$ & $\begin{array}{c}\text { Показатель уров- } \\
\text { ня стабильности } \\
\text { сорта (ПУСС) }\end{array}$ \\
\hline St. & Камелия & 10,61 & 24,58 & 0,43 & 4,58 \\
\hline 1 & Популяция 11/15 & 11,42 & 27,19 & 0,42 & 4,80 \\
\hline 2 & Мечта + Биотип 4 & 10,08 & 23,04 & 0,44 & 4,41 \\
\hline 3 & Популяция 10/14 & 9,38 & 24,76 & 0,38 & 3,55 \\
\hline 4 & ПП урожай 07 & 9,71 & 23,99 & 0,40 & 3,93 \\
\hline 5 & Популяция 08 & 10,89 & 23,68 & 0,46 & 5,01 \\
\hline 6 & Стабильная & 9,82 & 23,30 & 0,42 & 4,14 \\
\hline НСР & 1,00 & & & \\
\hline \multicolumn{2}{|l|}{ Индекс условий среды (li $)$} \\
\hline
\end{tabular}


Параметры адаптивности сортообразцов люцерны по сбору сухого вещества

\begin{tabular}{|c|l|c|c|c|}
\hline №/Д & \multicolumn{1}{|c|}{ Сортообразец } & $\begin{array}{c}\text { Экологическая } \\
\text { адаптивность }(\mathrm{bi})\end{array}$ & $\begin{array}{c}\text { Стабильность } \\
\left(\mathrm{S}^{2} \mathrm{~d}_{1}\right)\end{array}$ & $\begin{array}{c}\text { Экологическая } \\
\text { устойчивость }\end{array}$ \\
\hline St. & Камелия & 0,95 & 3,00 & 5,73 \\
\hline 1 & Популяция 11/15 & 1,26 & 0,34 & 7,11 \\
\hline 2 & Мечта + Биотип 4 & 0,98 & 0,28 & 5,07 \\
\hline 3 & Популяция 10/14 & 0,93 & 0,68 & 5,51 \\
\hline 4 & ПП урожай 07 & 0,86 & 2,82 & 5,12 \\
\hline 5 & Популяция 08 & 1,05 & 0,09 & 5,79 \\
\hline 6 & Стабильная & 0,90 & 1,11 & 5,11 \\
\hline
\end{tabular}

стабильности сорта все образцы показали высокое значение данного признака - 3,555,01 . Лучшим результатом уровня стабильности по сбору сухого вещества и реакции на условия внешней среды характеризовались стандарт Камелия (ПУСС $=4,58)$, образцы: Популяция 11/15 (ПУСС $=4,80)$ и Популяция 08 (ПУСС = 5,01).

Другим важным показателем, определяющим устойчивость проявления реакций сорта в разных условиях среды, является показатель индекса стабильности. Изучаемые сортообразцы имели достаточно высокий индекс стабильности для данной культуры $(И С=0,38-0,46)$. При возделывании на кормовые цели при благоприятных и экстремальных (засуха или избыточное увлажнение) условиях выращивания люцерна проявляет толерантность к большинству стрессоров и формирует относительно стабильную урожайность.

Лучшие значения данного признака отмечены у стандарта Камелия и образцов Мечта + Биотип 4, Популяция $08-$ ИС = 0,43-0,46, что говорит о их приспособленности к конкретным условиям среды. Анализ экологической устойчивости показал, что самый низкий показатель отмечен у образцов Мечта + Биотип 4, Стабильная и ПП урожай $07-5,07-5,12$, что свидетельствует о наличии широкого диапазона приспособленности к стрессовым условиям произрастания (табл. 2).

Изучаемые сортообразцы в различных погодных условиях при возделывании на корм характеризовались высокой экологической адаптивностью и пластичностью, значения bi были близки к 1 и варьировали в пределах 0,86-1,26.

Комплексная оценка люцерны изменчивой по сбору сухого вещества показала, что все сортообразцы конкурсного сортоиспытания формируют достаточно высокую и стабильную продуктивность в различные по климатическим условиям годы. Но лучшими по экологической адаптивности и стабильности были сортообразцы Популяция 10/14 и Стабильная, параметры адаптивности которых составили $b i=0,90$ 0,98 и $\sigma \mathrm{dr}^{2}=0,68-1,11$ при средней продуктивности 9,38-9,82 т/га соответственно.

При возделывании на семена индекс условий среды варьировал в довольно широких пределах от - 0,15 до + 0,15 единиц. Как и при возделывании на корм, наиболее стрессовые условия для развития вегетативной массы люцерны сложились в 2015 году, величина индекса условий среды составляет - 0,15. Наиболее оптимальными условиями для роста и развития люцерны сложилась в 2013 год с показателем индекса условий 0,15. В соответствии с условиями среды варьировала и средняя урожайность семян по сортообразцам люцер-

Таблица 3

Показатели варьирования урожайности семян сортообразцов люцерны в среднем за 2013-2016 г2.

\begin{tabular}{|c|c|c|c|c|c|}
\hline №/Д & Сортообразец & $\begin{array}{c}\text { Средняя уро- } \\
\text { жайность, } \\
\text { т/га }\end{array}$ & $\begin{array}{c}\text { Изменчивость } \\
\text { урожайности } \\
\text { Cv, \% }\end{array}$ & $\begin{array}{l}\text { Индекс ста- } \\
\text { бильности } \\
\text { (ИС) }\end{array}$ & $\begin{array}{c}\text { Показатель уровня } \\
\text { стабильности } \\
\text { сорта (ПУСС) }\end{array}$ \\
\hline st & Камелия & 0,55 & 9,4 & 0,58 & 0,32 \\
\hline 1 & Популяция 11/15 & 0,50 & 37,8 & 0,13 & 0,07 \\
\hline 2 & Мечта + Биотип 4 & 0,67 & 24,7 & 0,27 & 0,18 \\
\hline 3 & Популяция 10/14 & 0,44 & 45,9 & 0,10 & 0,04 \\
\hline 4 & ПП урожай 07 & 0,45 & 24,1 & 0,19 & 0,08 \\
\hline 5 & Популяция 08 & 0,50 & 27,4 & 0,18 & 0,09 \\
\hline 6 & Стабильная & 0,48 & 44,1 & 0,11 & 0,05 \\
\hline & $\mathrm{HCP}_{05}$ & 0,06 & & & \\
\hline \multicolumn{3}{|c|}{ Индекс условий среды $\left(\mathrm{l}_{\mathrm{i}}\right)$} & $-0,15 \ldots 0,15$ & & \\
\hline
\end{tabular}


Параметры адаптивности сортообразцов люцерны по урожайности семян

\begin{tabular}{|c|l|c|c|c|}
\hline №/Д & \multicolumn{1}{|c|}{ Сортообразец } & $\begin{array}{c}\text { Экологическая } \\
\text { адаптивность }(\mathrm{bi})\end{array}$ & $\begin{array}{c}\text { Стабильность } \\
\left(\mathrm{S}^{2} \mathrm{~d}_{1}\right)\end{array}$ & $\begin{array}{c}\text { Экологическая } \\
\text { устойчивость }\end{array}$ \\
\hline St. & Камелия & $-1,58$ & 0,12 & 0,09 \\
\hline 1 & Популяция 11/15 & $-1,05$ & 0,16 & 0,38 \\
\hline 2 & Мечта+Биотип 4 & $-1,54$ & 0,33 & 0,32 \\
\hline 3 & Популяция 10/14 & $-0,79$ & 0,12 & 0,40 \\
\hline 4 & ПП урожай 07 & $-1,04$ & 0,08 & 0,21 \\
\hline 5 & Популяция 08 & $-1,10$ & 0,12 & 0,26 \\
\hline 6 & Стабильная & $-0,90$ & 0,16 & 0,42 \\
\hline
\end{tabular}

ны. В среднем за 2013-2016 годы урожайность семян сортообразцов люцерны колебалась от 0,44 до 0,67 т/га (табл. 3).

Лучшим по урожайности семян люцерны является образец Мечта + Биотип 4 0,67 т/га (+ 21,8\% к st). Изменчивость урожайности семян была слабой у стандарта Камелия (Cv - 9,4\%), у образцов Популяция 8, Корнеотпрысковая 1 и Корнеотпрысковая - на среднем уровне ( $\mathrm{Cv}-24,1$ $27,4 \%$ ). Более высокий показатель и, соответственно, высокая вариация урожайности от 37,8 до $45,9 \%$ отмечена у трех образцов Популяция $11 / 15$, Стабильная, Популяция 10/14. Характеристика сортов по ПУСС показала, что значение данного признака варьировало в пределах 0,04-0,32.

Лучшими показателями по уровню стабильности, урожаю семян и реакции на условия внешней среды характеризовались сортообразцы Мечта + Биотип 4 (ПУСС = $0,18)$ и стандарт Камелия $(П У С С ~=0,32)$.

Индекс стабильности при возделывании на семена варьировал в пределах ИС = 0,10-0,58. При возделывании на семена при благоприятных и экстремальных условиях выращивания люцерна проявляет меньшую толерантность к стрессорам, чем при выращивании на корм. Лучшие значения данного признака имели образец Мечта + Биотип 4 и стандарт Камелия ИС $=0,27-0,58$, что говорит о их большей приспособленности к конкретным условиям среды.

Оценка экологической устойчивости показала, что низкие значения этого показателя отмечены у стандарта Камелия, образцов ПП урожай 07 и Популяция 08 0,09-0,26, что характеризует их как широко приспособленные к стрессовым условиям произрастания (табл. 4).

Изучаемые сортообразцы в различных погодных условиях при возделывании на семена характеризовались довольно высоким варьированием экологической адаптивности и пластичности, значения bi находились в пределах - 0,79-1,58.

Комплексная оценка люцерны изменчивой по урожайности семян показала, что не все сортообразцы имеют достаточно высокую и стабильную продуктивность в различные по климатическим условиям годы. Наиболее адаптивными по урожайности семян являются сортообразцы: Популяция $11 / 15$ (bi $\left.=-1,05 ; \sigma \mathrm{dr}^{2}=0,16\right)$, Стабильная (bi $\left.=-0,90 ; \sigma \mathrm{dr}^{2}=0,16\right)$ и ПП урожай 07 (bi = -1,04; $\left.\sigma \mathrm{dr}^{2}=0,08\right)$.

\section{Заключение}

Таким образом, результаты исследований показали, что в среднем за 2013-2016 гг. два сортообразца выделились по продуктивности и параметрам адаптивности. Популяция 11/15 формирует максимальный сбор сухого вещества - 11,4 т/га (+ $7,6 \%$ к st.), имеет индекс стабильности на уровне стандарта, высокий ПУСС - 4,8, экологическую адаптивность (bi = 1,26). По урожайности семян сортообразец имеет высокий показатель - 0,50 т/га, отличается адаптивностью и стабильностью (bi = -1,05; $\left.\sigma \mathrm{dr}^{2}=0,08\right)$ и экологической устойчивостью - 0,38. Мечта + Биотип 4 формирует сбор сухого вещества - 10,08 т/га, при средней изменчивости урожайности ( $\mathrm{Cv}-23,0 \%)$, индекс стабильности, ПУСС и показатель экологической устойчивости на уровне контроля - 0,44; 4,41 и 5,07, соответственно. Обладает высокой адаптивностью (bi = $0,98)$. По урожайности семян был лучшим среди всех сортообразцов - 0,67 т/га $(+$ $21,1 \kappa$ st.), при средних показателях изменчивости урожайности (Cv - 24,7\%). Индекс стабильности составляет - 0,27, ПУСС 0,18 , экологическая адаптивность на уровне стандарта (bi = -1,54).

\section{Лumepamypa}

1. Растениеводство: биология и приёмы возделывания на Юго-Востоке / В.Г. Васин, Н. Н. Ельчанинова, А. В. Васин, А. В. Зорин, С. Н. Зудилин. - Самара, 2003. - 360 с.

2. Володина, И. А. Оценка исходного материала люцерны изменчивой для селекции высокопродуктивных сортов в условиях Среднего Поволжья: автореферат диссертации на соискание ученой степени кандата с.-х. наук / И. А. Володина. - Кинель, 2015.- 18 с. 
3. Груза, Г. В. Колебания и изменения климата на территории России / Г. В. Груза, Э. Я. Ранькова // Известия РАН. ФАО. - 2003. - Т. 39. - № 2. - С. 166-185.

4. Диагностика устойчивости растений к стрессовым воздействиям: методическое руководство / под ред. Г.В.Удовенко. - Ленинград: ВНИИ растениеводства им. Н. И. Вавилова (ВИР), 1988. - 228 с.

5. Епифанова, И. В. Оценка образцов люцерны на засухоустойчивость в условиях лесостепи Среднего Поволжья / И. В. Епифанова, О. А. Тимошкин // Международный сельскохозяйственный журнал. - 2018. - № 4 (364). - 2018. - С. 48-51.

6. Епифанова, И. В. Приёмы возделывания люцерны изменчивой Дарья на кормовые цели в условиях лесостепи Среднего Поволжья / И. В. Епифанова, О. А. Тимошкин // Международный сельскохозяйственный журнал. - 2018. - № 3 (363). - С. 36-38.

7. Казарин, В.Ф. Использование индекса засухоустойчивости образцов люцерны в Поволжском регионе / В. Ф. Казарин, А. А. Курьяновия, И. А. Володина // Кормопроизводство. - 2015. № 12. - С. 7-14.

8. Кильчевский, А. В. Генетические основы селекции растений: общая генетика растений / А. В. Кильчевский, Л. В. Хотылева. - Минск, 2008. - Т. 1. - С. 50-56.

9. Королев, К. П. Оценка генотипов льна-долгунца (Linum usitatissimum L.) по экологической адаптивности и стабильности в условиях северо-восточной части Беларуси / К. П. Королев, Н. А. Боме // Сельскохозяйственная биология. - 2017. - Т. 52. - № 3. - С. 615-621.

10. Методические указания по селекции и первичному семеноводству многолетних трав. Москва: Россельхозакадемия, 1993. - 112 с.

11. Методические указания по селекции многолетних трав. - Москва: ВИР, 1985. - 188 с.

12. Неттевич, Э.Д. Потенциал урожайности рекомендованных для возделывания в Центральном районе РФ сортов яровой пшеницы и ячменя и его реализация в условиях производства / Э. Д. Неттевич // Доклады РАСХН. - 2001. - № 3. - С. 50-55.

13. Основные виды и сорта кормовых культур: итоги научной деятельности Центрального селекционного центра / ФГБНУ ВНИИ кормов им. В. Р. Вильямса РАН. - Москва: Наука, 2015. - 545 с.

14. Экологическая устойчивость и адаптивность сортов рыжика озимого / Т. Я. Прахова, Е. Л. Турина, Р. А. Кулинич, В. А. Прахов // Аграрная Россия. - 2017. - № 12. - С. 23-27.

15. Climate Change 2007: adaptation and Vulnerability. Contribution of Working Group II to the Fourth Assesment Report of the Intergovernmental Panel of Climate Change. - Cambridge, UK. - 23 p.

16. Eberhart, S. A. Stability parameters for comparing varieties / S. A. Eberhart, W. A. Russel // Crop. Sci. - 1966. - № 6. - P. 36-40.

17. Prakhova, T. Ya. Changes in the Fat-acidic Composition of Camelina sativa Oilseeds Depending on Hydrothermal Conditions/ T. Ya. Prakhova, V. A. Prakhov, M. V. Danilov // Russian Agricultural Sciences. - 2018. - V. 44. - № 3. - P. 221-223.

18. Rossielle, A. A. Theoretical aspects of selection for yield in stress and no stress environments / A. A. Rossielle, J. A. Hamblin // Crop Sci. - 1981. - № . 6. - P. 12-23.

UDC 633.31:631.526.32

DOI 10.36461/NP.2020.54.1.014

\section{EFFICIENCY AND ADAPTIVITY OF ALFALFA VARIETIES IN THE CONDITIONS OF THE FOREST-STEPPE OF THE MIDDLE VOLGA REGION}

\section{V. Epifanova, Candidate of Agricultural Sciences, O. A. Timoshkin, Doctor of Agricultural Sciences}

Federal State Budget Scientific Institution Federal Scientific Center of Bast Crops, Russia, Penza Region, the workers' settlement of Lunino, e-mail: oatimoshkin@mail.ru

The studies were carried out on the experimental field of the Penza Institute of Agriculture - a branch of Federal State Budget Scientific Institution Federal Scientific Center of Bast Crops in 20132016. The aim of the research was to evaluate the productivity of new alfalfa varieties and the parameters of their adaptability to limiting environmental factors when grown in a single-species cultivation. On average, over the years of research, the dry matter productivity of alfalfa varieties varied from 6.72 to $12.21 \mathrm{t} /$ ha depending on the index of environmental conditions (li-3.55-1.85). The best in productivity was the Populyatsiya $11 / 15$ variety with a yield of $11.42 \mathrm{t} /$ ha $(+7.6 \%$ to st.). The variability of dry matter productivity varied from 23.0 to $27.2 \%$, which characterizes the average stability of the trait. The studied alfalfa samples showed high environmental adaptability and plasticity, the bi values varied in the range of $0.86-1.26$. The most stable and flexible in terms of dry matter productivity were the following varieties: Stabilnaya $-\mathrm{bi}=0.90 ; \sigma \mathrm{dr}^{2}=1.11$; Populyatsiya $10 / 14-\mathrm{bi}=0.98 ; \sigma \mathrm{dr}^{2}=0.68$. The seed productivity of alfalfa samples on average over the years of research ranged from 0.36 to $0.67 \mathrm{t} /$ ha depending on the index of environmental conditions $(l i=-0.15 \ldots 0.15)$. 
The best variety in terms of seed yield was the Mechta + Biotype 4 variety $-0.67 \mathrm{t} / \mathrm{ha}(+21.8 \%$ to st.). The variability of seed yields of the Kamellia standard was weak - $9.4 \%$; the average yield variability (24.1-27.4\%) was in the Populyatsiya 8, Korneotpryskovaya 1 and Korneotpryskovaya 2 varieties. The Kamellia standard and Mechta + Biotype 4, which stability index (SI) was 0.18 and 0.32 , respectively, were characterized by a higher level of stability of the variety. The most stable and flexible varieties in terms of seed yield were the varieties: Populyatsiya $11 / 15-b i=-1.05 ; \sigma \mathrm{dr}^{2}=0.16$; Stabilnaya $-\mathrm{bi}$ $=-0.90 ; \sigma \mathrm{dr}^{2}=0.16$; PP urozhaj $07-\mathrm{bi}=-1.04 ; \sigma \mathrm{dr}^{2}=0.08$. bility.

Keywords: alfalfa, variety, competitive variety testing, collection of dry matter, seed yield, adapta-

\section{References:}

1. Plant growing: biology and methods of cultivation in the Southeast / V. G. Vasin, N. N. Elchaninova, A. V. Vasin, A. V. Zorin, S. N. Zudilin. - Samara, 2003.- 360 p.

2. Volodina, I. A. Assessment of variegated alfalfa starting material for selection of highly productive varieties in the Middle Volga region: an abstract of a dissertation for the degree of candidate of agricultural sciences / I. A. Volodina. - Kinel, 2015.- 18 p.

3. Gruza, G. V. Oscillations and climate change in Russia / G. V. Gruza, E. Ya. Rankova // Proceedings of the RAS. PAO - 2003. - V. 39. - № 2. - P. 166-185.

4. Diagnostics of plant resistance to stressful effects: a methodological guide / ed. by G. V. Udovenko. - Leningrad: All-Russian Research Institute of Plant Production named after N. I. Vavilov (VIR), 1988.- $228 \mathrm{p}$.

5. Epifanova, I. V. Assessment of alfalfa samples for drought tolerance in the conditions of the forest-steppe of the Middle Volga region / I. V. Epifanova, O. A. Timoshkin // International Agricultural Journal. - 2018.- № 4 (364). - 2018.- P. 48-51.

6. Epifanova, I. V. Methods of cultivating variegated alfalfa Daria for forage purposes in the conditions of the forest-steppe of the Middle Volga / I. V. Epifanova, O. A. Timoshkin // International Agricultural Journal. - 2018.- № 3 (363). - P. 36-38.

7. Kazarin, V. F. Using the drought tolerance index of alfalfa samples in the Volga region / V. F. Kazarin, A. A. Kuryanovia, I. A. Volodina // Fodder production. - 2015. - № 12. - P. 7-14.

8. Kilchevsky, A. V. Genetic basis of plant breeding: general plant genetics / A. V. Kilchevsky, L. V. Khotyleva. - Minsk, 2008. - V. 1. - P. 50-56.

9. Korolev, K. P. Assessment of genotypes of fiber flax (Linum usitatissimum L.) by environmental adaptability and stability in the conditions of the north-eastern part of Belarus / K. P. Korolev, N. A. Bome // Agricultural Biology. - 2017. - V. 52. - № 3. - P. 615-621.

10. Guidelines for selection and primary seed production of perennial herbs. - Moscow: Russian Agricultural Academy, 1993.- 112 p.

11. Guidelines for the selection of perennial herbs. - Moscow: VIR, 1985.- $188 \mathrm{p}$.

12. Nettevich, E. D. The potential yield recommended for cultivation in the Central region of the Russian Federation varieties of spring wheat and barley and its implementation in the conditions of production / E. D. Nettevich // Reports of RAAS. - 2001. - № 3. - P. 50-55.

13. The main types and varieties of forage crops: the results of scientific activities of the Central breeding center / FWRC FPA n. a. V. R. Williams of RAS. - Moscow: Nauka, 2015.- 545 p.

14. Ecological sustainability and adaptability of varieties of winter false flax / T. Ya. Prakhova, E. L. Turin, R. A. Kulinich, V. A. Prakhov // Agrarnaya Rossiya (Agrarian Russia). - 2017. - № 12. P. 23-27.

15. Climate Change 2007: adaptation and Vulnerability. Contribution of Working Group II to the Fourth Assesment Report of the Intergovernmental Panel of Climate Change. - Cambridge, UK. - 23 p.

16. Eberhart, S. A. Stability parameters for comparing varieties / S. A. Eberhart, W. A. Russel // Crop. Sci. - 1966. - № 6. - P. 36-40.

17. Prakhova, T. Ya. Changes in the Fat-acidic Composition of Camelina sativa Oilseeds Depending on Hydrothermal Conditions/ T. Ya. Prakhova, V. A. Prakhov, M. V. Danilov // Russian Agricultural Sciences. - 2018. - V. 44. - № 3. - P. 221-223.

18. Rossielle, A. A. Theoretical aspects of selection for yield in stress and no stress environments / A. A. Rossielle, J. A. Hamblin // Crop Sci. - 1981. - № . 6. - P. 12-23. 